University of Nebraska - Lincoln

DigitalCommons@University of Nebraska - Lincoln

2005

\title{
Abdominal Pigmentation Variation in Drosophila polymorpha: Geographic Variation in the Trait, and Underlying Phylogeography
}

Jennifer A. Brisson

University of Nebraska-Lincoln, jennifer.brisson@rochester.edu

Daniela Cristina De Toni

Universidade Federal De Santa Catarina, Brazil

Ian Duncan

Washington University in St Louis, duncan@wustl.edu

Alan R. Templeton

Washington University in St Louis

Follow this and additional works at: https://digitalcommons.unl.edu/bioscifacpub

Part of the Life Sciences Commons

Brisson, Jennifer A.; De Toni, Daniela Cristina; Duncan, Ian; and Templeton, Alan R., "Abdominal Pigmentation Variation in Drosophila polymorpha: Geographic Variation in the Trait, and Underlying Phylogeography" (2005). Faculty Publications in the Biological Sciences. 79.

https://digitalcommons.unl.edu/bioscifacpub/79

This Article is brought to you for free and open access by the Papers in the Biological Sciences at DigitalCommons@University of Nebraska - Lincoln. It has been accepted for inclusion in Faculty Publications in the Biological Sciences by an authorized administrator of DigitalCommons@University of Nebraska - Lincoln. 


\title{
Abdominal Pigmentation Variation in Drosophila polymorpha: Geographic Variation in the Trait, and Underlying Phylogeography
}

\author{
Jennifer A. Brisson, ${ }^{1}$ Daniela Cristina De Toni, ${ }^{2}$ Ian Duncan, ${ }^{1}$ and Alan R. Templeton ${ }^{1}$ \\ ${ }^{1}$ Department of Biology, Washington University, St. Louis, Missouri 63130 \\ ${ }^{2}$ Universidade Federal De Santa Catarina, CCB/BEG, Florianopolis, Santa Catarina, Brazil
}

Present address for J. A. Brisson - Department of Ecology and Evolutionary Biology, Princeton University, Princeton, New Jersey 08544

Present address for D. C. De Toni - Department of Biological Sciences, University of Notre Dame, Notre Dame, Indiana 46556

\begin{abstract}
Drosophila polymorpha is a widespread species that exhibits abdominal pigmentation variation throughout its range. To gain insight into this variation we combined phenotypic and genotypic data to test a series of nested hypotheses. First, we tested the null hypothesis that geographic variation in pigmentation is due to neutral factors. We used nested clade analysis to examine the distribution of haplotypes from a nuclear and a mitochrondrial locus. Restricted gene flow via isolation by distance, the primary inference of this phylogeographic analysis, was then used to generate and test the hypothesis of increasing average abdominal pigmentation difference with increasing geographic distance. We found no correlation between geographic distance and phenotypic distance. We then tested the hypothesis that pigmentation is affected by environmental differences among localities. We found a significant effect of habitat type on the average abdominal pigmentation phenotype of different localities. Finally, we tested the hypothesis that pigmentation in D. polymorpha is associated with desiccation resistance. We found that dark individuals of both sexes survived significantly longer in a desiccating environment than light individuals. These patterns combined lead us to hypothesize that abdominal pigmentation variation in D. polymorpha is important in mediating the organism's interactions with local ecological factors.
\end{abstract}

Keywords: abdominal pigmentation, cardini group, Drosophila polymorpha, phenotypic variation, phylogeography

Color polymorphisms have been of long-standing interest in evolutionary biology due to their visual accessibility and their utility as a trait amenable to genetic dissection (Dobzhansky 1937; Cain and Sheppard 1954; Kettlewell 1955; Gunnarsson 1985; King 1988; Reillo and Wise 1988; Gillespie and Tabashnik 1990; Brodie 1992; Andres et al. 2000; Hazel 2002). The popularity of these studies came in conjunction with controversies over whether or not this variation is the result of natural selection, i.e., whether or not color polymorphisms are adaptive (Cott 1940; Hooper 2002). On the one hand, the nonrandom distribution of a polymorphic phenotype could be a local response to heterogeneous environments. Conversely, neutral factors such as genetic drift, founder effects, and migration could be responsible if the trait is selectively neutral with respect to its surroundings. Both explanations must be considered to avoid adaptive storytelling, "just-so" stories (Gould and Lewontin 1979).

Modern molecular techniques allow the disentanglement of these two causative forces by making use of presumably neutral genetic markers. The geographic distribution of variation at these markers can provide a baseline expectation against which a putatively selected locus or phenotype can be overlaid to test the hypothesis that it is being acted upon by selection. If the two datasets exhibit different patterns, then the hypothesis that neutral factors are responsible for the observed variation can be rejected. A number of studies have employed this method with success in a variety of systems (Karl and Avise 1992; Pogson et al. 1995; Smith et al. 1997; Gillespie and Oxford 1998; Schmidt and Rand 1999; Andres et al. 2000; Brown et al. 2001; Storz 2002). For example, Andres et al. (2000) examined female color polymorphism in the damselfly Ischnura graellsii by comparing allele frequencies at the color locus with neutral random amplification of polymorphic DNA (RAPD). The differences in color morph frequencies between populations were significantly less than if they were determined solely by neutral, random factors. Thus, they concluded that purifying selection played a role in maintaining similar color morph frequencies across populations.

Abdominal pigmentation is a conspicuously variable, potentially adaptive trait in Drosophila. The variation is displayed among species groups (Garcia-Bellido 1983), between closely related species (Hollocher et al. 2000a), between sexes within a species (Kopp et al. 2000), and geographically within a species (Heed 1963; Lee 1963; Robertson et al. 1977; Ohnishi 1985). Recent studies of abdominal pigmentation in the genus have approached this phenotype from a variety of angles, including analyses of phenotypic plasticity (David et al. 1990; Gibert et al. 1998, 2000), the evolutionary developmental basis of intra- and interspecific differences (Kopp et al. 2000; Wittkopp et al. 2002a, 2002b), a phylogenetic and speciation context of trait evolution (Hollocher et al. 2000a, $2000 \mathrm{~b}$ ), and traditional quantitative trait loci approaches (Llopart et al. 2002; Kopp et al. 2003; Wittkopp et al. 2003a). Despite this growing literature (for recent reviews, see True 2003; Wittkopp et al. 2003b), few studies have provided significant insight into what function, if any, this trait plays in the genus. One recent notable exception is provided by Dombeck and Jaenike (2004), who demonstrated that D. falleni flies without abdominal spots were nearly twice as susceptible to nematode infection as wild-type, spotted flies.

Several general hypotheses exist for explaining pigmentation differences within or between species of invertebrates. For example, a pigmented, or melanized, cuticle can convey 
various physical properties, including heat absorption, ultraviolet protection, resistance to injury, and desiccation resistance (Kalmus 1941a; Kettlewell 1973; Hebert and Emery 1990; Kingsolver 1995; Majerus 1998; True 2003). In Drosophila, darkly pigmented morphs are thought to result from the ability of dark flies to absorb heat more readily than light flies, with darker phenotypes advantageous in cooler climates (Lee 1963; Robertson and Louw 1966; Gibert et al. 1996; Karan et al. 1998). A pigmentation polymorphism may allow the occupation of multiple niches in a complex habitat, and drive monomorphism in a comparably marginal habitat, or one in which there is competition with sympatric species (Heed 1963). Melanism can also be used defensively, as in the case of crypsis or warning coloration (Cott 1940). Finally, the evolution of melanization may be driven by sexual selection (Kettlewell 1973; Majerus 1998). Polymorphisms in pigmentation could be caused by any of these factors, either singly or in combination. Studies of abdominal pigmentation within or between species can potentially inform questions regarding the evolution of melanism in invertebrates generally.

The goal of this study was to examine the striking variation in abdominal pigmentation displayed by a widespread South American species of fruit fly, Drosophila polymorpha, to develop an understanding of why this trait is so variable in this species. We combined genetic and phenotypic data to test a series of nested hypotheses addressing the existence and maintenance of polymorphism in this trait. First, we looked for heterogeneity among the geographic distribution of pigmentation variation and the geographic variation in genetic markers unrelated to pigmentation (a mitochondrial DNA and a nuclear locus) to test the null hypothesis that differences in pigmentation between localities were a consequence of population structure factors. Upon rejection of this hypothesis, we posited that trait variation could be explained by environmental differences among localities. To test this, we examined the distribution of the phenotype across localities that differed in habitat to determine if there was a correlation between environmental characteristics and the pigmentation phenotype. Finally, after establishing a trait by environment correlation, we used laboratory experimentation to provide insight into the utility of variation in this trait to this species.

\section{Materials and Methods}

\section{Study Organism, Sampling, and Pigmentation Scoring}

Drosophila polymorpha is a member of the cardini group, which consists of 16 species distributed throughout the West Indies as well as North, Central, and South America. The group is unique in that it exhibits extensive abdominal pigmentation variants, with a range of patterns that are primarily fixed interspecifically, although several species are polymorphic for the trait (da Cunha 1949; Heed and Russell 1971; Hollocher et al. 2000a). The focal species of this study, Drosophila polymorpha, ranges as far north as Colombia, Venezuela, and Trinidad, and as far south as Argentina (Heed 1963) in all but the driest habitats (Sene et al. 1980), in cities, as well as natural areas (Tidon-Sklorz and Sene 1992; Tidon-Sklorz et al. 1994; Rohde and Valente 1996). The species exhibits conspicuous abdominal pigmentation variation: variants range

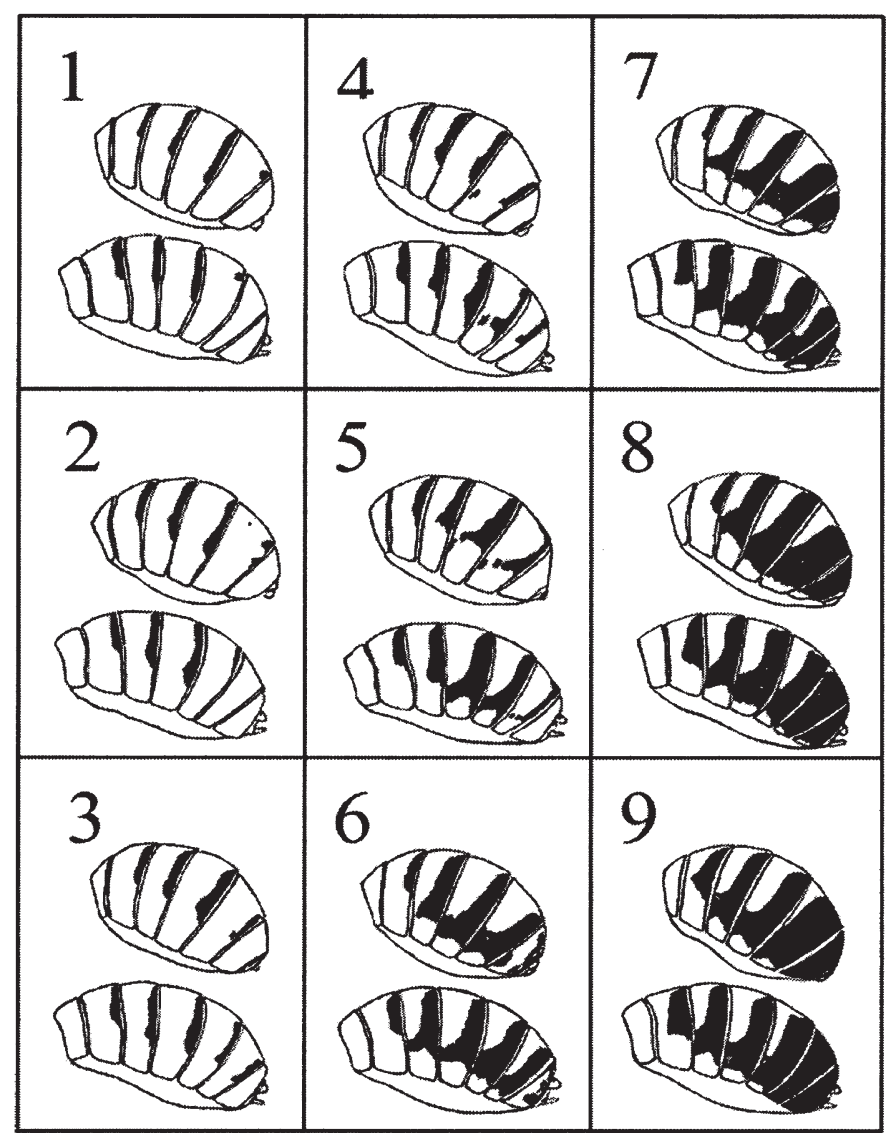

Figure 1. The nine abdominal pigmentation types of Drosophila polymorpha, based on the categorization scheme developed by Martinez and Cordeiro (1970). The top abdomen in each panel is that of the male, and the bottom is that of the female

from light, almost completely unpigmented morphs to dark, almost completely pigmented morphs (Figure 1). Further, abdominal pigmentation in D. polymorpha has a strong genetic basis. Initial crossing experiments by da Cunha (1949) determined that the polymorphism is caused by a single pair of alleles with no dominance. Heed and Blake (1963) subsequently established the existence of a third allele at the original locus, a dominant light allele found only in populations from northern South America. Still later, Martinez and Cordeiro (1970) discovered a modifier locus with two alleles that showed a variety of effects on the phenotype. The action of the modifier locus makes it impossible to infer directly allele types at the primarily locus from the pigmentation phenotype. All three studies made use of crossing experiments with offspring raised in a common environment. The entire range of phenotypes from light to dark was consistently produced, suggesting that if there is phenotypic plasticity in this trait in this species, then the proportion of the trait variation explained by environmental influences is much less than that proportion explained by genetic factors.

Sampling of Drosophila species was done during early morning hours using banana bait or orange/banana bait fermented with baker's yeast. Baits were set either on the ground, or in one-liter cans hung from vegetation roughly one meter above the ground. Individuals were collected from 21 different localities in Brazil (Table 1, Figure 2). All 
Table 1. List of sampling localities; $n_{1}$, number of individuals sequenced for the $c y t B$ (mtDNA) locus; $n_{2}$, number of individuals sequenced for the $p g d$ (nuclear) locus

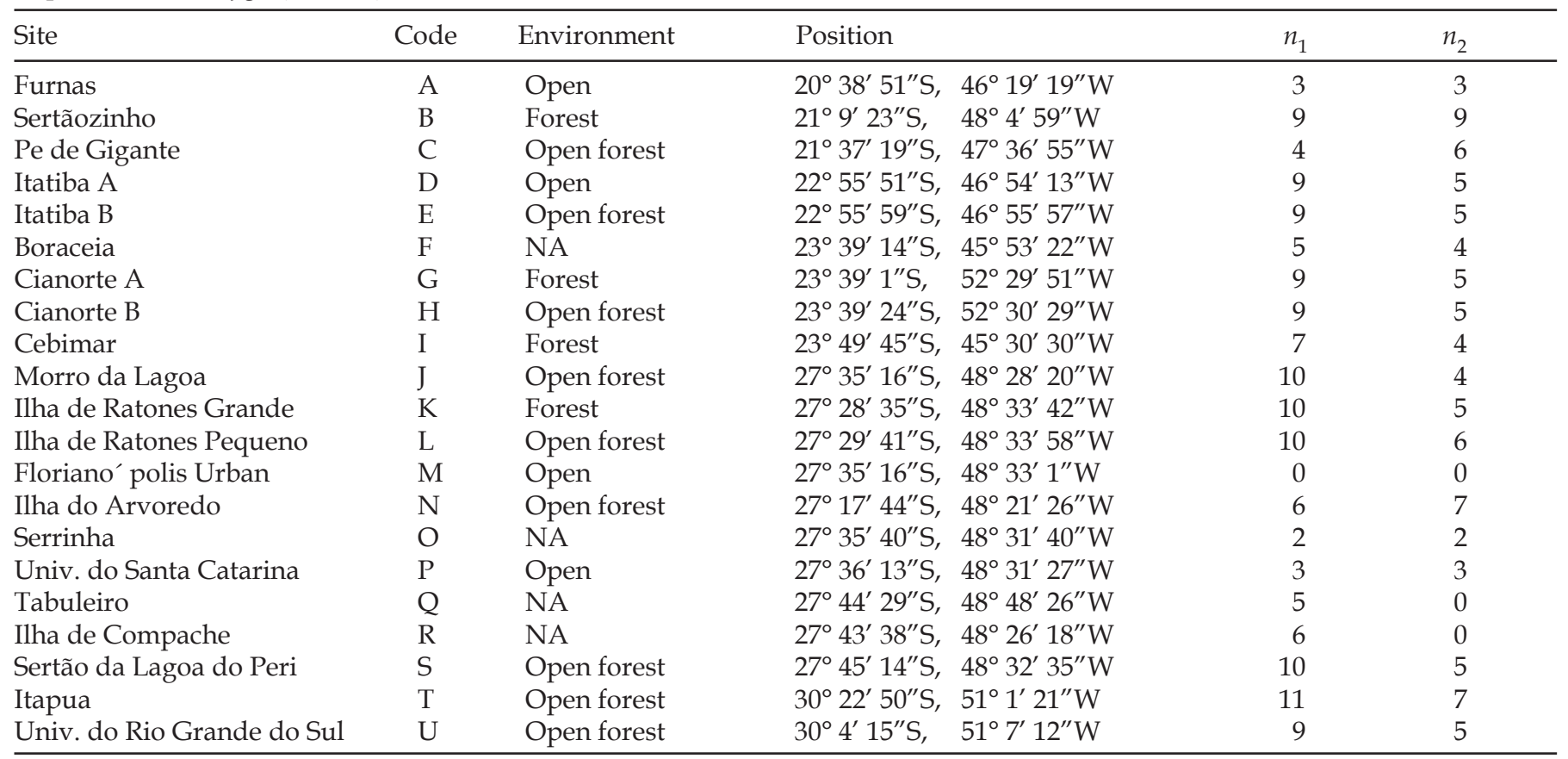

localities lay within the same approximate altitudinal range of 600 to $900 \mathrm{~m}$ above sea level. Two collecting trips were made: one in March through April of 2001, and one in March through May of 2002. Members of the cardini group were distinguished from other species groups using the key of Freire-Maia and Pavan (1949), and species within the cardini group were distinguished according to the key of Vilela et al. (2002). All individuals were examined by stereoscope and sexed. A single investigator (JAB) scored the pigmentation phenotype of all flies. Using a numbering scheme developed specifically for the abdominal pigmentation phenotypes of D. polymorpha by Martinez and Cordeiro (1970), individual animals were scored with a number from one (lightest) to nine (darkest) (Figure 1), and scoring was done blindly with respect to collection locale. Flies were not included if they were not yet fully pigmented due to their young age (pigmentation in this species begins as a grey color which darkens within a few days after emergence from the puparium).

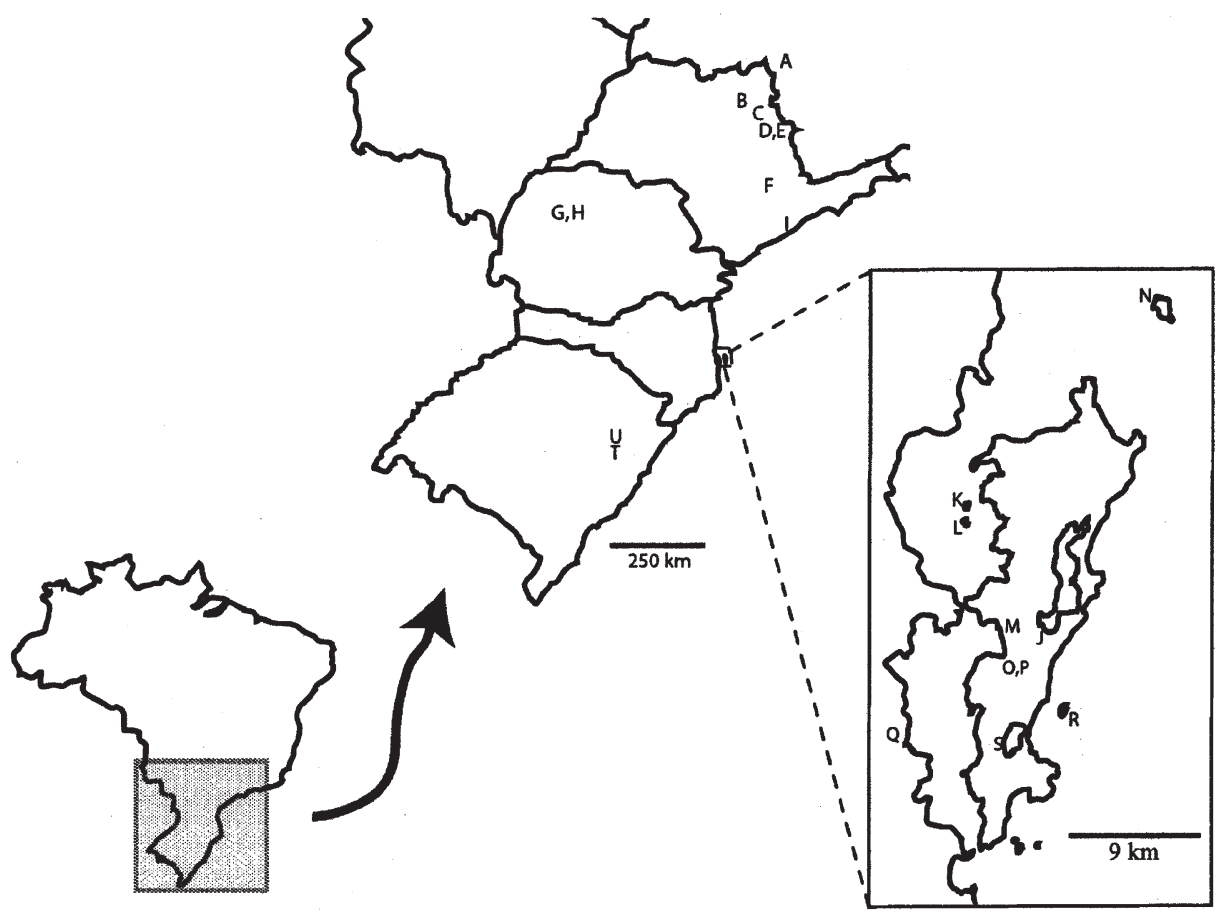

Figure 2. Map showing the sampling localities in southern Brazil. Letter abbreviations used for the localities are those from Table 1. The map on the right is a magnification of the framed part in the map on the left 
We coded the environment in which each population was found into three categories: "forest," "open forest," and "open." Forested areas had a dense canopy as well as a dense understory, with a humid, dark, cool environment and vegetation characteristic of Atlantic Forest. These areas had little disturbance due to humans or were in advanced regeneration stages. Open forests were those areas that had a canopy, but little to no understory, such that the area was less humid yet still largely not exposed to direct sunlight. Although typical Atlantic Forest vegetation occupied the majority of these areas, it was at different stages of succession due to habitat disturbance. Open areas were those that had either no trees, as in the case of a savannah, or were urban or farmland areas that had only extremely sparse trees such that the area was dry, warm, and generally exposed to the sun. These areas were typically considered highly disturbed habitats.

\section{Amplification and Sequencing of Haplotypes}

We extracted DNA from individual flies using a DNeasy Tissue Kit (Qiagen, Valencia, CA). Template for sequencing was amplified using the primers 10941 (5'-TTGAGGAGCTACTGTTATTAC-3') and 12580 (5'-TTGTTTAATAGGAATTCCTCAACC- $3^{\prime}$ ). These primers amplify a roughly $1600 \mathrm{bp}$ fragment which includes a portion of the cytochrome $b$ gene, the complete serine tRNA, and part of NADH dehydrogenase subunit one. Amplification was performed in 100 $\mu l$ reactions with Promega (Madison, WI) Taq DNA polymerase using a denaturation at $95^{\circ} \mathrm{C}$ for $30 \mathrm{sec}$, annealing at $50^{\circ} \mathrm{C}$ for $35 \mathrm{sec}$, and extension at $70^{\circ} \mathrm{C}$ for $150 \mathrm{sec}$ with $4 \mathrm{sec}$ added to the extension per cycle for 30 total cycles. Samples were purified on $2.5 \%$ acrylamide gels and passively eluted from the acrylamide for one to three days in Maniatis elution buffer (Maniatis et al. 1982). Purified double-stranded DNA was then used in $10 \mu l$ reactions with Big Dye chemistry (vers. 2, Applied Biosystems, Foster City, CA). Sequencing was performed using the PCR primers, as well as two internal primers: 11841 (5'-GGTACATTACCTCGGTTTCGTTATGAT-3') and 11670 (5'-ATGAGCTTGAACAAGCATATGTT-3'). All products were sequenced on both strands to ensure sequence accuracy. Products of the sequencing reactions were purified using CentriSep spin columns (Princeton Separations, Adelphia, NJ) and electrophoresed on a Basestation automated sequencer (MJ Research, Hercules, CA).

For comparative purposes, we also used a segment of the 6-phosphogluconate dehydrogenase ( $p g d$ ) locus on the Xchromosome that encodes an enzyme involved in the pentose-phosphate shunt (Gutierrez et al. 1989). We used the exon-based degenerate primers pgdfor (5'-GGAGCCGACTCGCTNGARGAYATG-3') and pgdrev (5'-CGCGGCCTCGTGNCCNCCNGGCAT-3') designed from known $p g d$ orthologues in GenBank to amplify a roughly $600 \mathrm{bp}$ region of an intron in $p g d$. We cloned amplified DNA into the pSTBlue-1 vector using the Acceptor Vector cloning kit (Novagen, San Diego, CA), and sequenced using the vector-specific primers T7 and U19. Due to the misincorporation rate of Taq polymerase, divergent sequences were reamplified and sequenced directly to check for polymerase chain reaction artifacts.
Molecular Analyses

Nested clade analysis (NCA) was used to examine the phylogeography of D. polymorpha (Templeton et al. 1995). Sequences were aligned by hand, and haplotype tree estimation using statistical parsimony (Templeton et al. 1992) was implemented using the program TCS version 1.13 (Clement et al. 2000). The haplotype tree was then used to define a series of hierarchically nested clades following the nesting rules given in Templeton et al. (1987) and Templeton and Sing (1993). The program GeoDis 2.0 (Posada et al. 2000) was used to calculate the NCA measures for each clade in each level of nesting: the clade distance $\left(D_{c}\right)$, which measures how geographically widespread the haplotypes are within a given clade, and the nested clade distance $\left(\mathrm{D}_{\mathrm{n}}\right)$, which measures how far the haplotypes within that clade are from the haplotypes of its evolutionarily closest sister clades (Templeton et al. 1995). Ten thousand random iterations were used to permute the observations within a nesting clade over geography, each time recalculating $\mathrm{D}_{\mathrm{c}}$ and $\mathrm{D}_{\mathrm{n}^{\prime}}$ to test the null hypothesis of no association of a haplotype in a cladogram with geographical position, as described in Templeton et al. (1995). When an association is found, significantly large or small $\mathrm{D}_{\mathrm{c}}$ and $\mathrm{D}_{\mathrm{n}}$ values are used to distinguish between events in the species' past (e.g., range expansion, fragmentation, bottlenecks, etc.) and recurrent evolutionary forces (e.g., isolation by distance) affecting the distribution of genetic diversity (inadequate sampling can also be detected). This method has the advantage of incorporating haplotype networks and geography within a rigorous statistical framework with no a priori hypotheses, and has been used successfully to distinguish population structure from population history in an ever-increasing number of species (e.g., Branco et al. 2002; de Brito et al. 2002) and its inference criteria have been extensively validated with a data base of 150 prior predictions (Templeton 2004). The programs TCS and Geodis, as well as the inference key outlined in Templeton (2004) are available at http://bioag.byu.edu/zoology/crandall_lab/ programs.htm. The comparison of haplotypes across localities was done using ChiPerm version 1.2 with 1000 Monte Carlo permutations.

\section{Phenotypic Analyses}

Pairwise geographic distances were calculated between all populations for which phenotypes were scored (17 populations). Additionally, pairwise phenotypic distances were calculated between the average phenotype in each of these populations. To assess whether there was an association between geographic distances and phenotypic distance, we used PASSAGE version 1.0 (Rosenberg 2002) to implement a Mantel test with 10,000 permutations. Because the variance of the abdominal pigmentation phenotype was not similar across populations, we analyzed the effect of the environment on mean population phenotype using distribution-free Jonckheere-Terpstra tests. We tested the null hypothesis of no effect of the environment on the average phenotype against an ordered alternative hypothesis. We used the same test to assess the null hypothesis that there is no effect of the environment on the standard deviation of the phenotype. Reported $P$-values are the highest possible with $99 \%$ confidence pro- 

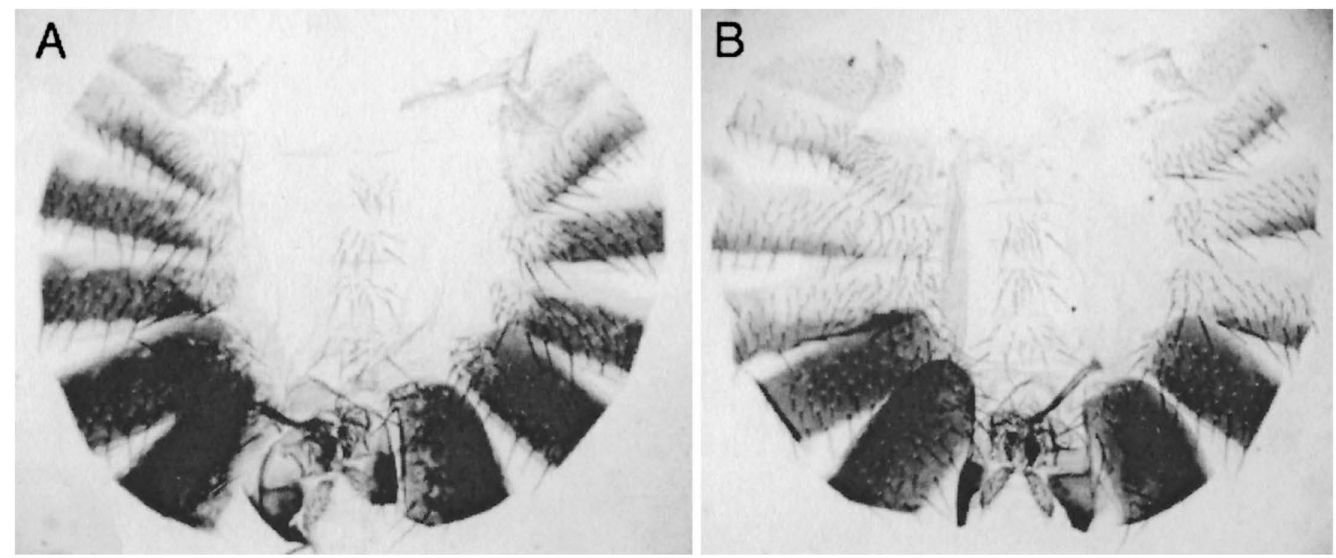

Figure 3. Abdominal pigmentation phenotypes of (A) $\mathrm{Qd}^{1}$ and (B) wild-type Drosophila melanogaster males. Abdomens are cut along the dorsal midline and flattened

duced by 10,000 Monte Carlo permutations. These statistical analyses were done using StatXact-5 version 5.0.3 (Cytel Software, Cambridge, MA). The comparison of phenotypes across localities was done using ChiPerm version 1.2 with 1000 Monte Carlo permutations.

\section{Desiccation Assays}

\section{Drosophila polymorpha}

Testing of water balance was done as described in Gibbs et al. (1997). Two different light lines were used: stock numbers 15191-2231.1 and 15191-2331.2 (National Drosophila Species Resource Center, Tucson, AZ), originally from Maraval, Trinidad, and Porto Alegre, Brazil, respectively. The dark line is a population line collected from Florianópolis, Brazil. We crossed light males of each line to virgin dark females. The resulting progeny were then crossed, and finally those progeny were crossed to produce the $\mathrm{F}_{2}$ generation flies used in this study. The two lines are referred to as lines one and two, where line one originated from dark flies crossed to light flies from strain 15191-2231.1, and line two originated from dark flies crossed to light flies from strain 15191- 2331.2. For the desiccation experiments, we used flies that were six to ten days posteclosion, and all females were virgins. We used light flies that had phenotypes of one and two, and their sibling dark flies that had phenotypes of eight and nine (see Figure 1). Due to the presence of a dominant light allele, these are the only phenotypic classes that could be produced. To determine the average mass of a fly of each sex and abdominal pigmentation phenotype, ten groups of three to six flies were etherized and weighed on a Cahn electrobalance. Each group was etherized separately and immediately weighed to minimize water loss prior to measurement. To test desiccation resistance, a single fly was placed in a $15 \mathrm{ml}$ screw-top tube (Corning) containing $7 \mathrm{~g}$ of Drierite. We used a total of 100 flies for each sex and line. The flies were placed in an incubator at $24^{\circ} \mathrm{C}$, checked hourly for survival, and weighed in groups of three after death. The flies were then dried overnight at $60^{\circ} \mathrm{C}$ and reweighed. Water content was the difference between initial mass and dry mass, divided by body mass, and water content at death was calculated as the difference between the mass at death and dry mass, divided by body mass. Differences in mass, water content, and water content at death were analyzed via Wilcoxon-Mann-Whitney test with 10,000 permutations to determine two-sided significance values as implemented in StatXact-5 version 5.0.3 (Cytel Software). Differences in survival curves between light and dark phenotypes were determined via Wilcoxon tests implemented in JMP version 5.0.1.2 (SAS Institute).

\section{Drosophila melanogaster}

The optomotor-blind (omb) locus encodes a T-box DNA-binding transcription factor that is necessary for the normal development of the central nervous system, legs, and wings (Brunner et al. 1992; Pflugfelder et al. 1992; Poeck et al. 1993; Grimm and Pflugfelder 1996). Relevant to this study, omb is also involved in patterning the adult abdomen (Kopp and Duncan 1997). The locus is complex, but a class of alleles, the $Q u a d r o o n(Q d)$ alleles, are known to only affect the abdomen (Banga et al. 1986; Pflugfelder et al. 1990; Kopp and Duncan 1997). Specifically, the $Q d^{1}$ mutation in the omb gene of $D$. melanogaster produces overly pigmented males (females are not as dramatically overpigmented, and therefore were not used here). Whereas wild-type males are typically pigmented in abdominal segments five and six, $Q d^{1}$ flies have ectopic pigmentation in abdominal segments three and four (Figure 3), but otherwise appear wildtype. We crossed $Q d^{1}$ flies to the isoA line of wild-type flies (an isogenic line derived from Canton-S) and permitted them to freely interbreed for one year. We collected newly eclosed males, allowed them to age for three days, and then tested wild-type versus darkly pigmented males for desiccation resistance as with $D$. polymorpha flies.

\section{Effect of Rearing Temperature}

To examine the effect of rearing temperature on abdominal pigmentation variation in D. polymorpha, we used the dark line (population line collected from Brazil) and the light line (15191-2331.2) mentioned above. 30 total crosses were set up in bottles, with 15 each of light $\times$ light and dark $\times$ dark. Each cross involved 30 males and 30 virgin females (larval survivorship is very poor for this species so many individuals must be used and kept in bottles, not vials). Five bottles of 
each morph were randomly assigned to one of three temperature treatments: $18^{\circ} \mathrm{C}, 21.5^{\circ} \mathrm{C}$, and $25^{\circ} \mathrm{C}$ (this species does not survive well at lower or higher temperatures). Egg laying was allowed for two days, and then the flies were transferred to a new bottle and randomly assigned to one of the two other temperatures, and then transferred to the last temperature treatment. After emergence, flies were aged for 20 days at the temperature at which they developed, and then the abdominal pigmentation phenotype was scored. Thirty flies of each sex were scored per bottle (when available).

\section{Results}

For the mtDNA dataset, a total of 44 haplotypes were identified out of 146 individuals from 20 locations (Table 1). No indels were encountered in the 1467 bases sequenced, and alignments were straightforward. Protein-coding regions were translated and did not have premature stop codons, signifying that the sequences analyzed here are from the mitochondrial genome and do not represent nuclear-integrated copies of mitochondrial genes. The nuclear intron, $p g d$, had two variable $(\mathrm{AC})_{\mathrm{n}}$ microsatellite regions as well as two indels (one of length 16, one of length 20) that were eliminated prior to analyses. The remaining 532 bases yielded 57 haplotypes from 90 individuals from 18 of the populations.

\section{Haplotype Relationships}

The haplotype network determined by the program TCS for the mtDNA dataset is presented in Figure 4A. Haplotypes separated by up to 16 steps had greater than $95 \%$ probability of being connected in a parsimonious fashion. The mtDNA haplotype network was straightforward. The majority of individuals $(59 \%)$ were found within three haplotypes, two of which were only two mutational steps away from one another, and a third which was 10 steps away from the closest of the first two. Fifty-five individuals fell within haplotype 28 , 29 within haplotype 1 , and 13 within haplotype 35 . However, the statistical parsimonious cladogram was not fully resolved, with ambiguities as illustrated in Figure 4A. There are three ways to connect haplotype 32 to the main part of the tree (to haplotypes 27, 30, or 31). The 32 to 31 connection is unlikely because of the frequency of the relative haplotypes and number of mutational steps required (Crandall and Templeton 1993). This leaves two alternatives, 32 to 30 and 32 to 27, both of which are possible. Therefore, analyses were done considering two alternative breaks, between haplotype 30 and the unobserved haplotype (from hereon referred to as analysis A) and between haplotypes 27 and the unobserved haplotype (from hereon referred to as analysis B). Finally, the ambiguity in the connections among haplotypes $32,33,34$, and 35 did not affect the nesting scheme, so it was not necessary to resolve.

The haplotype network determined by statistical parsimony for the $p g d$ (nuclear) dataset is presented in Figure 4B. Haplotypes separated by up to nine steps had greater than $95 \%$ probability of being connected in a parsimonious fashion. Once again, three haplotypes contained the majority of the individuals, although in this case single mutational steps separated these three common haplotypes. Haplotype
A
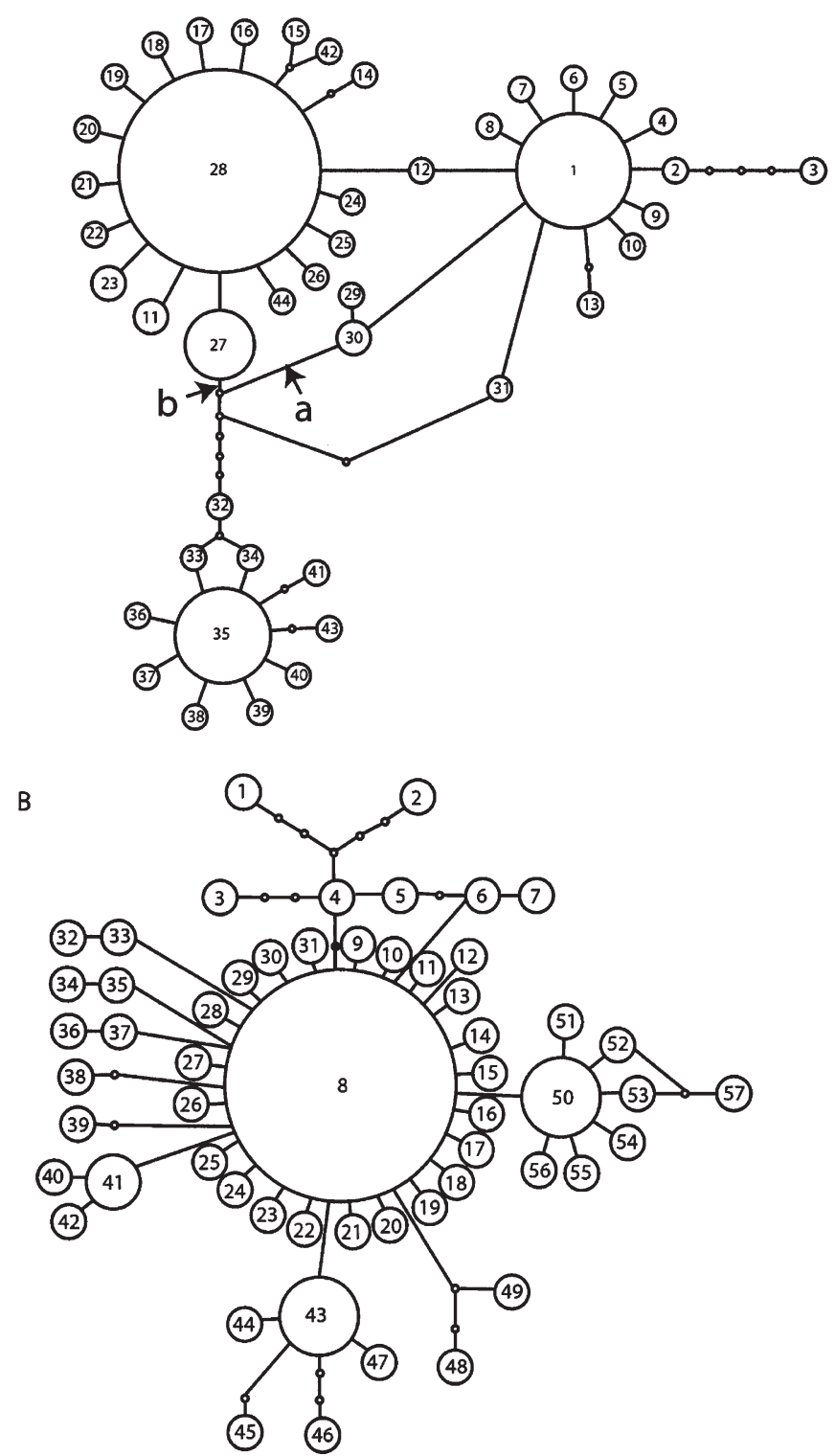

Figure 4. Network of (A) mtDNA haplotypes and (B) nuclear haplotypes determined by statistical parsimony. Each numbered circle represents a single haplotype and is sized relative to the number of individuals bearing that particular haplotype. Each small, closed circle represents an unsampled haplotype necessary for connection of the sampled haplotypes. Each line represents a single mutational step. The letters " $a$ " and " $b$ " refer to two alternative ways of breaking an amibiguity that were used in the nested clade analysis

8 had 24 of the individuals, haplotype 43 had four individuals, and seven individuals were within haplotype 50 . There were three ambiguities in the $p g d$ haplotype network. The first, concerning the connection of haplotypes 1 through 7 to haplotype 8 , was broken between haplotypes 6 and 8 due to the lesser number of mutational steps required compared with breaking this ambiguity between haplotype 4 and the unobserved haplotype. The second ambiguity, affecting the connection of haplotype 57, was broken between 52 and the 
Table 2. Chain of inferences and resulting inference for each significant result from the nested clade analysis for each of the two analyses, A and B

\begin{tabular}{lccll}
\hline Locus & Analysis & Clade & Chain of Inference & Inference \\
\hline mtDNA & A & $1-1$ & $1-2-3-4-N O$ & Restricted gene flow via isolation by distance \\
mtDNA & A & $1-4$ & $1-2-11-17-4-$ & NO Restricted gene flow via isolation by distance \\
mtDNA & A & $2-2$ & $1-2-11-17$ & Inconclusive \\
mtDNA & A & $2-3$ & $1-2-3-4-N O$ & Restricted gene flow via isolation by distance \\
mtDNA & A & $3-2$ & $1-2-11-12-N O$ & Contiguous range expansion \\
mtDNA & B & $1-1$ & $1-2-3-4-N O$ & Restricted gene flow via isolation by distance \\
mtDNA & B & $1-4$ & $1-2-11-17-4-N O$ & Restricted gene flow via isolation by distance \\
mtDNA & B & $2-3$ & $1-2-3-4-N O$ & Restricted gene flow via isolation by distance \\
mtDNA & B & $3-1$ & $1-2-11-17-4-N O$ & Restricted gene flow via isolation by distance \\
mtDNA & B & $3-2$ & $1-2-11-12-N O$ & Contiguous range expansion \\
$p g d$ & & $1-8$ & $1-2-11-17-4-N O$ & Restricted gene flow via isolation by distance \\
$p g d$ & & $1-14$ & $1-2-3-4-N O$ & Restricted gene flow via isolation by distance \\
$p g d$ & & $2-3$ & $1-2-11-17-4-N O$ & Restricted gene flow via isolation by distance \\
$p g d$ & & $2-4$ & $1-2-11-12-N O$ & Contiguous range expansion \\
\hline
\end{tabular}

unobserved haplotype. Finally, there was an ambiguity concerning a potential connection between haplotype 53 and 39 (ambiguity not shown). This was broken to leave 39 connected via one mutational step to haplotype 8 due to relative frequencies of the haplotypes and the lesser number of mutational steps this requires.

\section{NCA Inferences}

Nesting of the mtDNA dataset for the NCA was done as represented in Figure 5, with separate nestings for the two different analyses (4A and 4B). In analysis A, significant associations between haplotypes and geography were found at three levels of nesting (Table 2). At the one-step clade level, both clades 1-1 and 1-4 had inferences of restricted gene flow via isolation by distance. The same results were seen at the next level of nesting in clade 2-3. Finally, at the three-step level, clade 32 lead to an inference of contiguous range expansion.

Analysis B yielded nearly identical results (Table 2). Clades 1-1, 1-4, and 2-3 all lead to inferences of restricted gene flow via isolation by distance. However, in this analysis an additional inference of isolation by distance was detected at the three-step level (clade 3-1). Once again, we detected a contiguous range expansion event with clade 3-2.

Nesting of the $p g d$ haplotype tree was as in Figure 5C. Consistent with the mtDNA results, at the one-step clade level (clades 1-8 and 1-14) there were two inferences of restricted gene flow via isolation by distance (Table 2). This inference was also obtained at the two-step level (clade 2-3). Finally, we detected a contiguous range expansion event (clade 2-4).

\section{Genetic and Phenotypic Differences among Populations}

We tested for significant genetic differentiation across all sampling locations in a geographically unordered fashion. We could not reject the null hypothesis of homogeneity across all locations for the mitochondrial haplotypes $(P=$ $0.427)$, and similarly for the $p g d$ haplotypes $(P=0.511)$. Conversely, the frequencies of phenotypes were significantly different among localities $(P<0.001)$. Similarly, pairwise comparisons of phenotypic differences among populations found 47 of 136 (35\%) comparisons significant in contrast to no comparisons of mtDNA haplotypes, and only one comparison of $p g d$ haplotypes.

\section{Natural Variation in Abdominal Pigmentation}

The average phenotypes for both sexes separately and combined for each locality are listed in Table 3 and illustrated in Figure 6. The population with the darkest average abdomen was $\mathrm{P}$, with an average pigmentation of 8.61 on a scale from one to nine. The population with the lightest average abdomens was $\mathrm{G}$, with an average pigmentation phenotype of 6.50 . With the exception of a single population $(G)$, males displayed a higher average phenotype than females. Overall, we observed individuals of all phenotypes (one through nine of Figure 1), but the darkest phenotypes were the most common.

We found a strong effect of environment on the mean average phenotype of the flies, whether or not sexes were examined separately (Table 4). Populations from more open environments had a mean abdominal pigmentation phenotype that was higher than those from open forests, which in turn had mean phenotypes higher than those from forested areas. These effects were still significant after the removal of two locations with low sample sizes (localities A and C). There was also a relationship between the standard deviation of the average phenotypes and the environment (Table 4). The standard deviation was highest in the forested environments, lower in the open forests, and lowest in the open areas.

Sampling localities ranged in distance from one another, with the shortest distance between two localities being a single kilometer and the largest distance being $1066 \mathrm{~km}$. The correlation between the two distance measures as determined by Mantel test was nonsignificant $(P=0.116)$ with a correlation of 0.149 .

\section{Desiccation Resistance}

Measurements of water content and desiccation resistance are listed in Table 5, and survivorship curves are shown in Figure 7. Although mass differed significantly between the two lines for males and females, it did not differ significantly between color morphs within a line. Dark females of line one survived significantly longer in a desiccating environment than light females of line one, with the dark survivorship curve signif- 

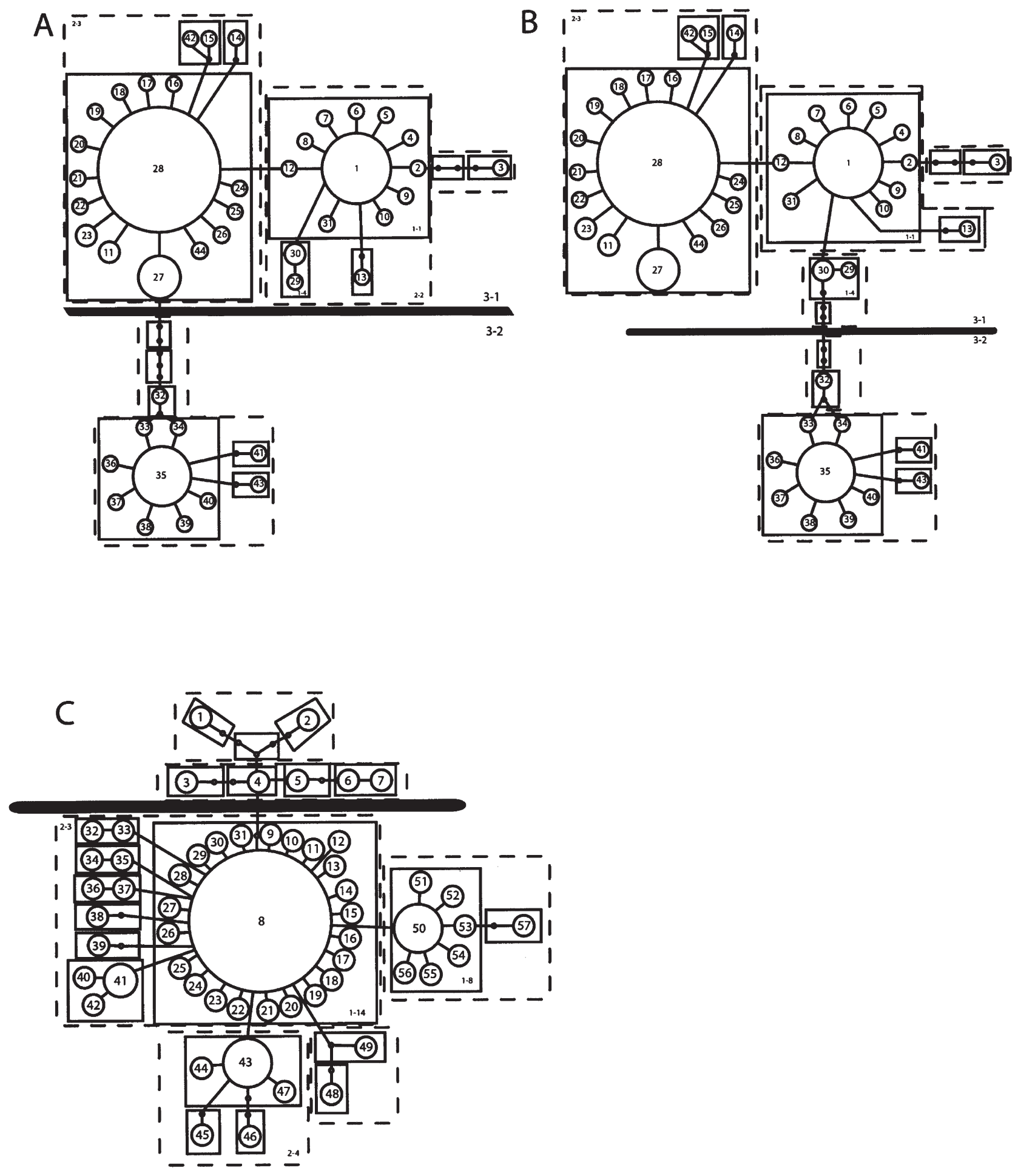

Figure 5. Nesting design used for the nested clade analysis for two alternative ways of breaking the ambiguity in the mtDNA dataset (A and B), as well as the nuclear dataset (C). Clade designations are numbered within each nesting level. Solid lines outline one-step clades. Broken lines outline two-step clades. The singe heavy dark line separates the two three-step clades. Two alternative ways of breaking the ambiguity outlined in Figure 3 are represented in (A) analysis A and (B) analysis B

icantly different than the light survivorship curve at the $P=$ 0.001 level. Dark males of line one also survived longer than light males of line one $(P=0.029)$. Similarly, dark females of line two survived significantly longer in dry air than light females of line two $(P=0.001)$, and dark males of line two survived longer than light males of line two $(P<0.001)$. There were no differences in survival time between the two lines of light female flies or between the dark female strains. Nor were there differences within color morphs between the two lines of light males or dark males. Water content and water content at death were not significantly different between color morphs of the same sex within a line. 
Table 3. List of the average phenotype (Avg.), standard deviation (SD), and number of individuals scored ( $n$ ) for each locality coded as in Table 1. Females and males are considered separately as well as combined

\begin{tabular}{|c|c|c|c|c|c|c|c|c|c|c|}
\hline \multirow[b]{2}{*}{ Locality } & \multirow[b]{2}{*}{ Environment } & \multicolumn{3}{|c|}{ Females } & \multicolumn{3}{|c|}{ Males } & \multicolumn{3}{|c|}{ Total population } \\
\hline & & Avg. & SD & $n$ & Avg. & SD & $n$ & Avg. & SD & $n$ \\
\hline A & Open & 7.50 & 0.71 & 2 & 8.50 & 0.71 & 2 & 8.00 & 0.82 & 4 \\
\hline $\mathrm{C}$ & Open forest & 8.00 & 0.00 & 2 & 8.50 & 0.71 & 2 & 8.25 & 0.50 & 4 \\
\hline $\mathrm{D}$ & Open & 7.67 & 0.58 & 3 & 8.31 & 0.48 & 16 & 8.21 & 0.54 & 19 \\
\hline $\mathrm{E}$ & Open forest & 7.33 & 1.37 & 6 & 8.47 & 0.51 & 17 & 8.17 & 0.94 & 23 \\
\hline I & Forest & 6.60 & 1.35 & 15 & 7.80 & 1.10 & 5 & 6.90 & 1.37 & 20 \\
\hline $\mathrm{J}$ & Open forest & 7.48 & 1.19 & 25 & 8.25 & 1.02 & 73 & 8.05 & 1.12 & 98 \\
\hline K & Forest & 7.34 & 1.08 & 29 & 8.09 & 0.88 & 139 & 7.96 & 0.96 & 168 \\
\hline $\mathrm{L}$ & Open forest & 7.76 & 1.03 & 17 & 8.32 & 0.75 & 71 & 8.22 & 0.84 & 88 \\
\hline M & Open & 7.67 & 1.05 & 15 & 8.86 & 0.36 & 14 & 8.24 & 0.99 & 29 \\
\hline $\mathrm{U}$ & Open forest & 6.43 & 1.40 & 7 & 8.10 & 0.57 & 10 & 7.41 & 1.28 & 17 \\
\hline
\end{tabular}

A similar result was observed in D. melanogaster. Although the overpigmented $Q d^{1}$ flies were significantly smaller than the wild-type males $(P=0.001)$, they survived significantly longer $(P<0.001)$. Once again, water content, and water content at death were not significantly different between the two phenotypes (Table 5).

\section{Effect of Rearing Temperature}

We raised $D$. polymorpha of either light or dark phenotypes in three different temperatures, $18^{\circ} \mathrm{C}, 21.5^{\circ} \mathrm{C}$, and $25^{\circ} \mathrm{C}$. Survivorship was low at the lowest and highest temperatures, with eight bottles at $18^{\circ} \mathrm{C}$, two bottles at $21.5^{\circ} \mathrm{C}$, and nine bottles at $25^{\circ} \mathrm{C}$ producing no offspring. Light individuals of both sexes raised at all three temperatures displayed no variation, displaying a phenotypic score of one. Similarly, all dark males were scored as nine. The only class that displayed variation was that of the dark females. This class produced abdominal pigmentation phenotypes of eight and nine, but showed no trend across the different temperatures (the average phenotype for all three temperatures was 8.9).

\section{Discussion}

Phenotypic variation in a character among individuals of a species can be affected by a multitude of factors, including population structure. Employing molecular markers to determine the phylogeography of a species of interest provides

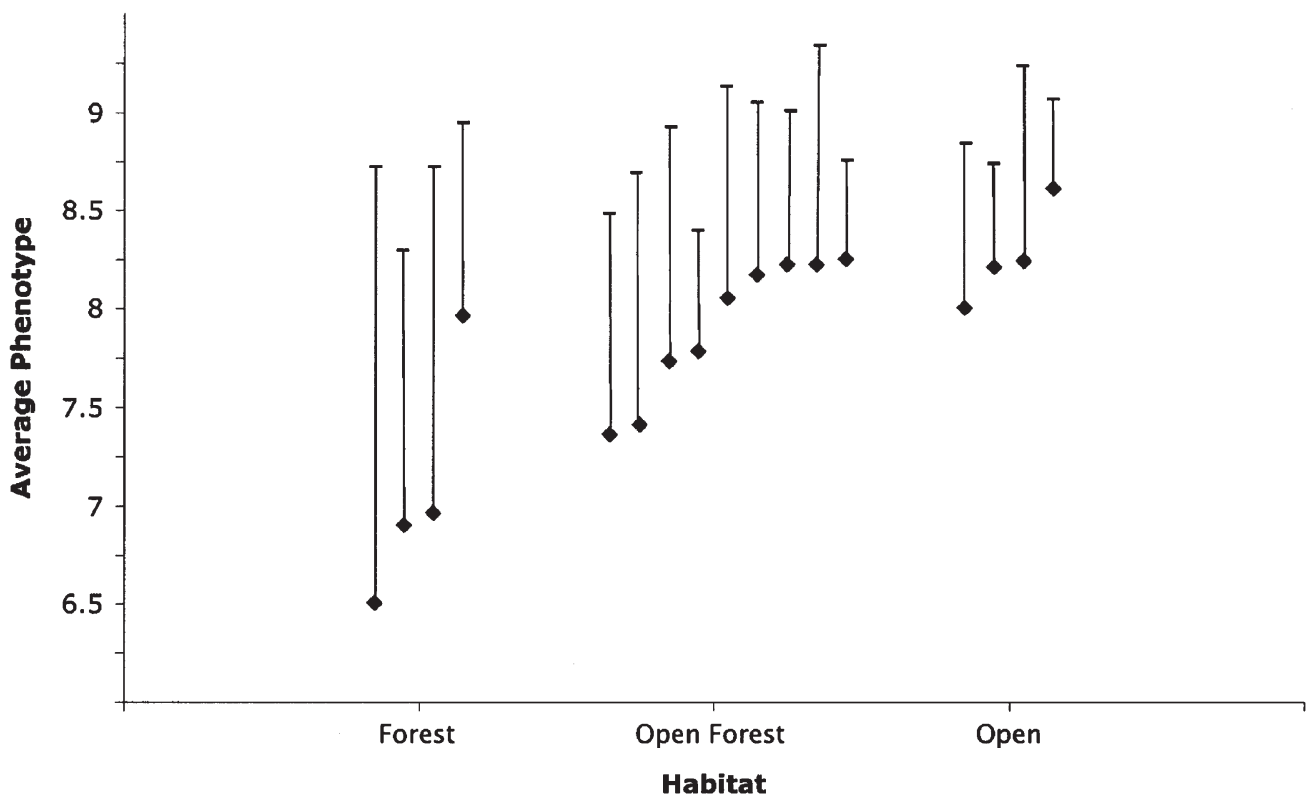

Figure 6. The average abdominal pigmentation phenotypes for each of the three habitat types. The bar represents one standard deviation. 
Table 4. Results of Jonckheere-Terpstra tests examining whether there is an effect of the environment on the average abdominal pigmentation phenotype of a population and whether there is an effect of the environment on the standard deviation of the abdominal pigmentation phenotype. df refers to the degrees of freedom, $J$ is the Jonckheere-Terpstra test statistic, and the $P$ value reported is two sided

\begin{tabular}{|c|c|c|c|c|c|c|}
\hline & \multicolumn{3}{|c|}{$\begin{array}{c}\text { Environment vs. } \\
\text { average } \\
\text { pigmentation }\end{array}$} & \multicolumn{3}{|c|}{$\begin{array}{l}\text { Environment vs. } \\
\text { standard deviation } \\
\text { of pigmentation }\end{array}$} \\
\hline & $\mathrm{df}$ & $J$ & $P$ & $\mathrm{df}$ & $J$ & $P$ \\
\hline Females & 2 & 73.0 & 0.019 & 2 & 22.0 & 0.030 \\
\hline Males & 2 & 86.5 & 0.001 & 2 & 12.5 & 0.003 \\
\hline Total population & 2 & 77.0 & 0.001 & 2 & 17.0 & 0.009 \\
\hline
\end{tabular}

a baseline expectation on which phenotypic variation can be considered. Here we apply this general method to the system of D. polymorpha, which displays conspicuous variation in a phenotype, abdominal pigmentation, which may mediate some aspect of how these flies interact with the multiple habitats in which they live.

\section{Phylogeography of Drosophila polymorpha}

Our analysis of mtDNA haplotypes of D. polymorpha distributed across southern Brazil using NCA detected one primary inference: restricted gene flow via isolation-by-distance. This inference was not only obtained regardless of how an ambiguity in the mtDNA haplotype network was broken, but was seen in the nuclear dataset as well. We therefore conclude that the main factor affecting gene flow in this species is geographical distance. In other words, in any given generation, a particular haplotype is expected to move over only a very small geographic distance, and haplotype ranges increase with time. This is not a surprising result, given that D. polymorpha is a relatively common species found in all but the driest of environments (Sene et al. 1980; Vilela et al. 2002), and therefore probably has a more-or-less continuous distribution in southern Brazil. Another statistically significant inference was an indication of contiguous range expansion (i.e., historically the species moved into a previously unoccupied area adjacent to the ancestral range). However, the direction of expansion is biologically ambiguous because the haplotypes involved in the range expansion events are found in the majority of the populations in a geographically nonclustered manner. Nevertheless, all of the NCA inferences are crossvalidated by mtDNA and nuclear DNA, indicating that the inferences are biologically sound and statistically valid, even for loci with different effective sizes (Templeton 2004). Perhaps more significant than the finding of isolation by distance was the lack of evidence for historical events, such as fragmentation, which could have contributed to abdominal pigmentation phenotype breaks among populations.

\section{Geographic Patterns of Pigmentation Variation}

The goal of our phylogeographic study of D. polymorpha was to serve as a baseline for examining geographic patterns of abdominal pigmentation variation. We therefore used the result, isolation by distance, to test the hypothesis that isolation by distance accounts for the nonrandom geographical distribution of the average abdominal pigmentation phenotype. Under this hypothesis, we expected the average phenotypic distance to increase with increasing geographic distance. This is not the case. To the contrary, a Mantel test showed that there was no relationship between phenotypic distance and geographic distance, with some close populations having large average phenotypic differences, and some distant populations having nearly identical phenotypes. We therefore reject the hypothesis that isolation by distance alone can account for the distribution of the pigmentation phenotype. This conclusion was supported when we compared either mtDNA and $p g d$ haplotypes or abdominal pigmentation phenotypes across sampling localities. We observed no differences in haplotype distributions across localities using a permutation test (this test lacks the statistical power of NCA because locations are geographically unordered, categorical variables, and is therefore not expected to pick up patterns of isolation by distance), but did find a highly significant difference in phenotypes across localities.

The picture that emerges from these analyses is that there is little to no population structure in this species (i.e., it is near panmixia with modest isolation by distance). In contrast, there is considerable abdominal pigmentation differentiation among populations. These contrasting patterns, taken together, suggest that population structure cannot account for abdominal pigmentation differences among populations.

\section{Correlations between Abdominal Pigmentation and the Environment}

Our phylogeographic analysis leads us to conclude that population structure is not responsible for abdominal pigmentation variation among sampling localities. However, pigmentation variation could still be distributed randomly with respect to the environment. Hence, we tested the hypothesis that habitat affects phenotypic distributions. As seen in Table 4, the environment has a highly significant effect on the average phenotype of a population. The direction of the effect is also clear: the dark humid environments found in closed forests are associated with average phenotypes that are lighter than those found in open, dry environments. Further, the standard deviations of the phenotypes are much larger in forested environments, with these environments possibly able to support a wider range of phenotypes than the open environments. In fact the most open environments typically have flies that only exhibit a range equivalent to the two darkest phenotypic classes (phenotypes 8 and 9 in Figure 1). In contrast, the forested environments, which may present a wider range of microhabitats, are more likely to display the entire range of phenotypes that this species produces $(P<$ $0.025, F$-ratio variance test comparing forested versus open or open forest environments). Alternatively, this same pattern could be produced if the darkest phenotypes were produced via a larger range of genetic variation than the intermediate phenotypes.

Several factors can account for this association of pigmentation phenotype with the environment, including habitat selection, phenotypic plasticity, and local adaptation. Habitat selection was not examined in this study, and warrants future experimentation. Several lines of evidence suggest that 
Table 5. Average mass, water content, and desiccation resistance of males and females of Drosophila polymorpha and males of wildtype pigmentation versus $Q d^{1}$ mutants of $D$. melanogaster. SD denotes standard deviation

\begin{tabular}{|c|c|c|c|c|c|c|}
\hline Strain & Species & Sex & Wet mass (mg) & Water content & $\begin{array}{c}\text { Water content } \\
\text { at death }\end{array}$ & $\begin{array}{l}\text { Average desiccation } \\
\text { time in hours (SD) }\end{array}$ \\
\hline Dark (1) & D. polymorpha & Male & 1.33 & $70.7 \%$ & $34.1 \%$ & $3.8(1.6)$ \\
\hline Dark (2) & D. polymorpha & Male & 1.10 & $67.6 \%$ & $40.7 \%$ & $3.8(1.7)$ \\
\hline Light (2) & D. polymorpha & Male & 1.09 & $66.5 \%$ & $37.8 \%$ & $2.8(0.9)$ \\
\hline Dark (1) & D. polymorpha & Female & 1.93 & $67.7 \%$ & $32.4 \%$ & $5.0(1.3)$ \\
\hline Light (2) & D. polymorpha & Female & 1.63 & $67.0 \%$ & $35.2 \%$ & $4.1(1.1)$ \\
\hline Wild-type & D. melanogaster & Male & 0.71 & $61.3 \%$ & $46.3 \%$ & $3.0(1.0)$ \\
\hline$Q d 1$ & D. melanogaster & Male & 0.63 & $60.7 \%$ & $47.5 \%$ & $3.8(1.2)$ \\
\hline
\end{tabular}

the majority of the variation in abdominal pigmentation in D. polymorpha is not due to phenotypic plasticity. First, previous studies on the genetics underlying the abdominal pigmentation phenotype in D. polymorpha (da Cunha 1949; Heed and Blake 1963; Martinez and Cordeiro 1970) utilized crossing experiments that produced offspring with a range of abdominal pigmentation phenotypes when raised in a common environment. Second, in multiple species of Drosophila that do show phenotypic plasticity for this trait, there is a specific pattern to that plasticity: increasing developmental temperature results in less pigmentation (David et al. 1990; Gibert et al. 1998; Gibert et al. 2000; Dombeck and Jaenike 2004). Therefore, if this trait is environmentally influenced in other species, there is an established predictable pattern to it. We observed the opposite pattern in D. polymorpha where the higher temperatures of the open environments were associated with the darkest flies. However, the possibility exists that $D$. polymorpha displays a different norm of reaction than previously examined species. Finally, we raised dark and light lines of D. polymorpha at three different temperatures and observed no temperature by phenotype effect. Unfortunately we were unable to produce individuals of inter- mediate pigmentation due to a dominant light allele carried by our light stock, and phenotypic plasticity is most likely to be observed in the intermediate morphs.

Regardless of the cause, there is a correspondence of abdominal pigmentation with habitat differences, and therefore the trait in D. polymorpha may be an important factor mediating its interaction with its habitat. A full understanding of the evolutionary process leading to the result observed here of a phenotype-habitat correlation will require disentangling the possible contributions of habitat selection, phenotypic plasticity, and local adaptation.

\section{Melanism Hypotheses in Drosophila polymorpha}

As previously mentioned, there are three primary adaptive explanations for melanism in invertebrates: defense (including crypsis and warning coloration), sexual selection, and physical adaptation (thermal melanism, UV-protection, resistance to injury) (Kettlewell 1973; Majerus 1998). Drosophila polymorpha is not an unpalatable species, and the variation it exhibits does not make it cryptically colored in the habitats in which it lives. Further, males and females are

\section{Line 1}

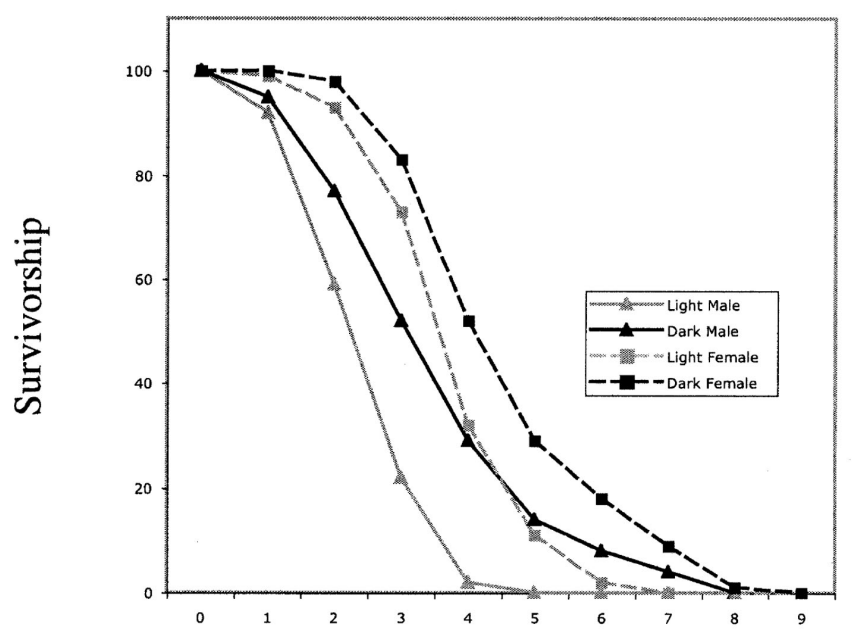

\section{Line 2}

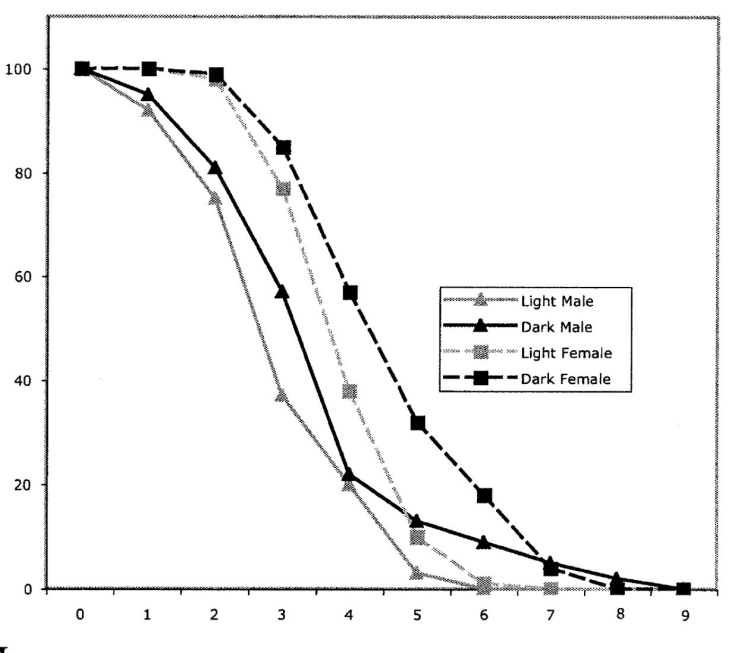

Figure 7. Survivorship of Drosophila polymorpha of lines one (left) and two (right). 
both darker in open environments and lighter in forested environments, males are darker on average than females in most cases, and there is no assortative mating by color type (da Cunha 1949). Therefore, neither defense nor sexual selection appears to be driving the melanistic differences in $D$. polymorpha among populations.

Physical properties remain to explain the patterns observed. Under a thermal adaptation argument, darker flies are expected in cooler environments, and lighter flies are expected in warmer environments. Indeed, several investigators have invoked this explanation for other species in the genus (Lee 1963; Robertson and Louw 1966; Gibert et al. 1996; Karan et al. 1998). However, D. polymorpha exhibits the opposite pattern: lighter flies, on average, are in cooler environments and darker flies are in warmer environments. Therefore, abdominal pigmentation differences among populations do not appear to be due to thermal melanism. However, Machado et al. (2001) found a higher abundance of darker individuals of $D$. polymorpha in winter months of seasonal collections in Santa Catarina, Brazil. Although this is superficially supportive of a thermal adaptation hypothesis, it could alternatively be explained as a consequence of seasonal humidity differences, especially in a tropical to subtropical environment, where seasons are marked by wet (summer) and dry (winter) time periods.

Another factor that varies among the localities in which $D$. polymorpha occurs is aridity. We investigated desiccation resistance in D. polymorpha and found that dark flies, both males and females, survived significantly longer in a desiccating environment than light flies. Further, because water content and water content at death were not significantly different between dark and light morphs, it is the slower rate of water loss in the dark flies that leads to their longer survival time. Two potential factors could account for this pattern. First, the primary gene(s) underlying abdominal pigmentation could be linked to genes involved in desiccation resistance. This is a plausible scenario given that the flies we tested were of the $\mathrm{F}_{2}$ generation, and therefore the genetic backgrounds of the light versus dark flies were not completely homogenized. Alternatively, the pigmentation of the cuticle could be directly affecting water loss by slowing transpiration through the cuticle. In support of the latter explanation are our experimental results of desiccation resistance in D. melanogaster wild-type versus ectopic abdominal pigmentation mutants (in which the genetic background was indeed homogenized). As in $D$. polymorpha, overpigmented $D$. melanogaster flies survive significantly longer in a desiccating environment, and wildtype and overpigmented flies loose the same amount of water before death, indicating it is once again the rate of water loss that differs between the two phenotypes. Interestingly, because males are smaller than females and therefore more prone to desiccation, the slowing of water loss through the cuticle by pigmentation may have been one of presumably many factors contributing to the evolution of sexually dimorphic pigmentation in some species groups.

The link between pigmentation and desiccation resistance was initially proposed by Kalmus $(1941 a, b, c)$. He tested this association by comparing the desiccation resistance of wildtype flies to yellow (light body color) and ebony (dark body color) mutants in D. melanogaster, and wild-type to yellow flies in D. simulans, D. pseudoobscura, and D. subobscura. The ebony mutants survived the longest, and the yellow mutants the shortest. He later showed that ebony mutants of D. melanogaster outcompeted wild-type flies at low humidities (Kalmus 1945). The work of Fraenkel and Rudall (1940) and Pryor (1940) provided further support for this connection between melanization and lower permeability of the cuticle. Both studies determined that the darkening and hardening traits of the cuticle are due to the same biochemical processes. Further, the darkening and hardening of the cuticle probably involves the cross-linking of proteins with melanin, as the hardest parts of insects are also black (Ashburner and Wright 1980; Neville 1975).

A number of mechanisms underlie desiccation resistance in Drosophila (reviewed by Hoffmann and Harshman 1999), including lowered metabolic rate, decreased water loss rate, and increased wet weight. Increased pigmentation may emerge as just one more way for flies to cope with this important ecological characteristic. Whether or not abdominal pigmentation affects UV resistance or resistance to injury are hypotheses that need to be tested in the future. Indeed, Heed and Krishnamurthy (1959) speculated on the connection between pigmentation in the cardini group and ecological factors such as UV radiation and aridity. Also unknown is what factor(s), if any, are acting to maintain, on average, lighter pigmented flies in more forested environments. Overall, multiple factors could be simultaneously driving abdominal pigmentation variation in D. polymorpha, as in other examples of color polymorphisms (Jones et al. 1997; True 2003).

\section{Abdominal Pigmentation as a Potential Adaptation in the Cardini Group}

Sene et al. (1980) examined the distribution of the four species of the cardini group that occur throughout much of Brazil. They found that $D$. neocardini is restricted to the most forested areas, D. polymorpha is found in all but the most dry, open places, and D. cardinoides and D. cardini are found mostly in dry, open places. Drosophila neocardini is a species with a light abdomen in southern Brazil (it exhibits intermediate morphs as well in some parts of its range [da Cunha 1955], very similar to the light to intermediate morphs of D. polymorpha). Conversely, D. cardini and D. cardinoides are very dark species in southern Brazil, as dark as, or even darker than the darkest morphs of D. polymorpha. Two interesting points emerge from this information. First, the most variable of the species, D. polymorpha, is able to exploit the widest range of habitats. Second, the association of the abdominal pigmentation phenotype with the environment that is seen intraspecifically with $D$. polymorpha is mirrored at the interspecific level within the cardini group, suggesting that abdominal pigmentation may be an adaptive phenotype underlying diversification in this group.

\section{Acknowledgments}

We are grateful to many people for their help, especially $\mathrm{V}$. Valente, P. Hofmann, F. Sene, M. Martins, S. Matioli, R. Mateus, and L. Lupaes. Special thanks also to C. Vilela for demonstrations on how to distinguish species in the cardini group, and for access to museum specimens. J. Chase and three anon- 
ymous reviewers for Evolution provided helpful comments on earlier drafts. JAB is a Howard Hughes Medical Institute Predoctoral Fellow. This work was supported by National Science Foundation DDIG grant number DEB-0104977 to JAB.

\section{Literature Cited}

Andres, J. A., R. A. Sanchez-Guillen, and A. C. Rivera. 2000. Molecular evidence for selection on female color polymorphism in the damselfly Ischnura graellsii. Evolution 54:2156-2161.

Ashburner, M. and T. R F. Wright. 1980. Genetics and biology of Drosophila. 2D. Academic Press, New York.

Banga, S. S., B. T. Bloomquist, R. K. Brodberg, Q. N. Pye, D. C. Larrivee, J. M. Mason, J. B. Boyd, and W. L. Pak. 1986. Cytogenetic characterization of the $4 \mathrm{BC}$ region on the $\mathrm{X}$ chromosome of Drosophila melangoaster: localization of the mei-9, norpA, and omb genes. Chromosoma 93:341-346.

Branco, M., M. Monnerot, N. Ferrand, and A. R. Templeton. 2002. Postglacial dispersal of the European rabbit (Oryctolagus cuniculus) on the Iberian Peninsula reconstructed from nested glade and mismatch analyses of mitochondrial DNA genetic variation. Evolution 56:792-803.

Brodie, E. D. 1992. Correlational selection for color pattern and antipredator behavior in the garter snake Thamnophis ordinoides. Evolution 46:1284-1298.

Brown, A. F., L. M. Kann, and D. M. Rand. 2001. Gene flow versus local adaptation in the northern acorn barnacle, Semibalanus balanoides: insights from mitochondrial DNA variation. Evolution 55:1972-1979.

Brunner, A., R. Wolf, G. O. Pflugfelder, B. Poeck, and M. Heisenberg. 1992. Mutations in the proximal region of the optomotor-blind locus of Drosophila melanogaster reveal a gradient of neuroanatomical and behavioral phenotypes. J. Neurogenet 8:43-50.

Cain, A. J. and P. M. Sheppard. 1954. Natural selection in Cepaea. Genetics 39:89-116.

Clement, M., D. Posada, and K. A. Crandall. 2000. TCS: a computer program to estimate gene genealogies. Mol. Ecol 9:1657-1660.

Cott, H. B. 1940. Adaptive coloration in animals. Oxford Univ. Press, New York.

Crandall, K. A. and A. R. Templeton. 1993. Empirical tests of some predictions from coalescent theory with applications to intraspecific phylogeny reconstruction. Genetics 134:959-969.

da Cunha, A. 1955. Sobre duas racas de Drosophila neocardini streisinger. Rev. Brasil. Biol 15:117-125.

da Cunha, A. B. 1949. Genetic analysis of the polymorphism of color pattern in Drosophila polymorpha. Evolution 3:239-251.

David, J. R., P. Capy, and J. P. Gauthier. 1990. Abdominal pigmentation and growth temperature in Drosophila melanogaster, similarities and differences in the norms of reaction of successive segments. J. Evolution. Biol 3:429-445.

de Brito, R. A., M. H. Manfrin, and F. M. Sene. 2002. Nested cladistic analysis of Brazilian populations of Drosophila serido. Mol. Phyl. Evol 22:131-143.

Dobzhansky, T. G. 1937. Genetics and the origin of species. Columbia Univ. Press, New York.

Dombeck, I. and J. Jaenike. 2004. Ecological genetics of abdominal pigmentation in Drosophila falleni: a pleiotropic link to nematode parasitism. Evolution 58:587-596.

Fraenkel, G. and K. M. Rudall. 1940. A study of the physical and chemical properties of the insect cuticle. Proc. R. Soc. Lond. Ser. B 129:1-35.

Freire-Maia, N. and C. Pavan. 1949. Chave para a determinacao das especies brasileiras de Drosophila. Cultus 5:57-61.

Garcia-Bellido, A. 1983. Comparative anatomy of cuticular patterns in the genus Drosophila. Development and evolution: the sixth symposium of the British Society for developmental biology. Cambridge Univ, New York.

Gibbs, A. G., A. K. Chippindale, and M. R. Rose. 1997. Physiological mechanisms of evolved desiccation resistance in Drosophila melanogaster. J. Exp. Biol 200:1821-1832.
Gibert, P., B. Moreteau, J. C. Moreteau, and J. R. David. 1996. Growth temperature and adult pigmentation in two Drosophila sibling species: an adaptive convergence of reaction norms in sympatric populations? Evolution 50:2346-2353.

Gibert, P., B. Moreteau, S. M. Scheiner, and J. R. David. 1998. Phenotypic plasticity of body pigmentation in Drosophila: correlated variations between segments. Genet. Sel. Evol 30:181-194.

Gibert, P., B. Moreteau, and J. R. David. 2000. Developmental constraints on an adaptive plasticity: reaction norms of pigmentation in adult segments of Drosophila melanogaster. Evol. Dev 2:249-260.

Gillespie, R. G. and G. S. Oxford. 1998. Selection on the color polymorphism in Hawaiian happy-face spiders: Evidence from genetic structure and temporal fluctuations. Evolution 52:775-783.

Gillespie, R. G. and B. Tabashnik. 1990. Maintaining a happy face: stable colour polymorphism in the spider Theiridion grallator (Araneae, Theridiidae). Heredity 65:67-74.

Gould, S. J. and R. C. Lewontin. 1979. The spandrels of San Marco and the Panglossian paradigm: a critique of the adaptationist programme. Proc. R. Soc. Lond. B 205:581-598.

Grimm, S. and G. O. Pflugfelder. 1996. Control of the gene optomotorblind in Drosophila wing development by decapentaplegic and wingless. Science 271:1601-1604.

Gunnarsson, B. 1985. Melanism in the spider Pityohyphantes phrygianus C. L. Koch: the genetics and the occurrence of different color phenotypes in a natural population. Heredity 59:55-62.

Gutierrez, A. G., A. C. Christensen, J. E. Manning, and J. C. Lucchesi. 1989. Cloning and dosage compensation of the 6-phosphogluconate dehydrogenase gene $(\mathrm{Pgd}++)$ of Drosophila melanogaster. Dev. Genet 10:155-161.

Hazel, W. N. 2002. The environmental and genetic control of seasonal polyphenism in larval color and its adaptive significance in a swallowtail butterfly. Evolution 56:342-348.

Hebert, P. D N. and C. J. Emery. 1990. The adaptive significance of cuticular pigmentation in Daphnia. Funct. Ecol 4:703-710.

Heed, W. B. 1963. Density and distribution of Drosophila polymorpha and its color alleles in South America. Evolution 17:502-518.

Heed, W. B. and P. R. Blake. 1963. A new color allele at the e locus of Drosophila polymorpha from Northern South America. Genetics 48:217-234

Heed, W. B. and N. B. Krishnamurthy. 1959. Genetic studies on the cardini group of Drosophila in the West Indies. Univ. Texas Publ 5914:155-179.

Heed, W. B. and J. S. Russell. 1971. Phylogeny and population structure in island and continental species of the cardini group of Drosophila studied by inversion analysis. Univ. Texas Publ 7103:91-130.

Hoffmann, A. A. and L. G. Harshman. 1999. Desiccation and starvation resistance in Drosophila: patterns of variation at the species, population and intrapopulation levels. Heredity 83:637-643.

Hollocher, H., J. L. Hatcher, and E. G. Dyreson. 2000a. Evolution of abdominal pigmentation differences across species in the Drosophila dunni subgroup. Evolution 54:2046-2056.

Hollocher, H., J. L. Hatcher, and E. G. Dyreson. 2000b. Genetic and developmental analysis of abdominal pigmentation differences across species in the Drosophila dunni subgroup. Evolution 54:2057-2071.

Hooper, J. 2002. Of moths and men: an evolutionary tale. The untold story of science and the peppered moth. Norton, New York.

Jones, J. S., B. H. Leith, and P. Rawlings. 1997. Polymorphism in Cepaea: a problem with too many solutions? Annu. Rev. Ecol. Syst 8:109-143.

Kalmus, H. 1941a. The resistance to desiccation of Drosophila mutants affecting body colour. Proc. R. Soc. Lond. B 130:185-201.

Kalmus, H. 1941b. Relation between colour and permeability of the insect cuticles. Nature 147:455.

Kalmus, H. 1941c. Physiology and ecology of cuticle colour in insects. Nature 148:428-431.

Kalmus, H. 1945. Adaptative and selective responses of a population of Drosphila melanogaster containing e and e+ to differences in termperature, humidity, and to selection for developmental speed. J. Genet 47:58-63. 
Karan, D., A. K. Munjal, P. Gibert, B. Moreteau, R. Parkash, and J. R. David. 1998. Latitudinal clines for morphometrical traits in Drosophila kikkawai: a study of natural populations from the Indian subcontinent. Genet. Res 71:31-38.

Karl, S. A. and J. C. Avise. 1992. Balancing selection at allozyme loci in oysters - Implications from nuclear RFLPs. Science 256:100-102.

Kettlewell, B. 1973. The evolution of melanism. The study of a recurring necessity; with species reference to industrial melanism in the Lepidoptera. Clarendon Press, Oxford, U.K.

Kettlewell, H. B D. 1955. Selection experiments on industrial melanism in the Lepidoptera. Heredity 9:323-342.

King, R. B. 1988. Polymorphic populations of the garter snake Thamnophis sirtalis near Lake Erie Canada/USA. Herpetologica 44:451-458.

Kingsolver, J. G. 1995. Viability selection on seasonally polyphenic traits: wing melanin pattern in western white butterflies. Evolution 49:932-941.

Kopp, A. and I. Duncan. 1997. Control of cell fate and polarity in the adult abdominal segments of Drosophila by optomotor-blind. Development 124:3715-3726.

Kopp, A., I. Duncan, and S. B. Carroll. 2000. Genetic control and evolution of sexually dimorphic characters in Drosophila. Nature 408:553-559.

Kopp, A., R. M. Graze, S. Z. Xu, S. B. Carroll, and S. V. Nuzhdin. 2003. Quantitative trait loci responsible for variation in sexually dimorphic traits in Drosophila melanogaster. Genetics 163:771-787.

Lee, T. J. 1963. Genetic analysis of the polymorphism of color pattern in Drosophila auraria. Dros. Inf. Serv 37:97-98.

Llopart, A., S. Elwyn, D. Lachaise, and J. A. Coyne. 2002. Genetics of a difference in pigmentation between Drosophila yakuba and Drosophila santomea. Evolution 56:2262-2277.

Machado, M. X., D. C. De Toni, and P. R P. Hofmann. 2001. Abdominal pigmentation polymorphism of Drosophila polymorpha (Dobzhansky and Pavan, 1943) collected on Ilha de Santa Catarina and neighboring islands. Biotemas 14:87-107.

Majerus, M. E N. 1998. Melanism: evolution in action. Oxford Univ. Press, Oxford, U.K.

Maniatis, T., E. F. Fritsch, and J. Sambrook. 1982. Molecular cloning: a laboratory manual. Cold Spring Harbor Laboratory Press, Cold Spring Harbor, NY.

Martinez, M. N. and A. R. Cordeiro. 1970. Modifiers of color pattern genes in Drosophila polymorpha. Genetics 64:573-587.

Neville, A. C. 1975. Biology of the arthropod cuticle. Springer-Verlag, New York.

Ohnishi, Sa T. K W. 1985. Genetic analysis of color dimorphism in the Drosophila montium subgroup. Jpn. J. Genet 60:355-358.

Pflugfelder, G. O., H. Schwarz, H. Roth, B. Poeck, A. Sigl, S. Kerscher, B. Jonschker, W. L. Pak, and M. Heisenberg. 1990. Genetic and molecular characterization of the optomotor-blind gene locus in Drosophila melanogaster. Genetics 126:91-104.

Pflugfelder, G. O., H. Roth, B. Poeck, S. Kerscher, H. Schwarz, B. Jonschker, and M. Heisenberg. 1992. The lethal(1)optomotor-blind gene of Drosophila melanogaster is a major organizer of optic lobe development: isolation and characterization of the gene. Proc. Natl. Acad. Sci. USA 89:1199-203.

Poeck, B., A. Hofbauer, and G. O. Pflugfelder. 1993. Expression of the Drosophilaoptomotor-blind gene transcript in neuronal and glial-cells of the developing nervous system. Development 117:1017-1029.

Pogson, G. H., K. A. Mesa, and R. G. Boutilier. 1995. Genetic population structure and gene flow in the Atlantic cod Gadus morhua: a comparison of allozyme and nuclear RFLP loci. Genetics 139:375-385.

Posada, D., K. A. Crandall, and A. R. Templeton. 2000. GeoDis: a program for the cladistic nested analysis of the geographical distribution of genetic haplotypes. Mol. Ecol 9:487-488.

Pryor, M. G M. 1940. On the hardening of the cuticle of insects. Proc. R. Soc. Lond. B 128:393-407.

Reillo, P. R. and D. H. Wise. 1988. An experimental evaluation of selection on color morphs of the polymorphic spider Enoplognatha ovata (Araneae, Theridiidae). Evolution 42:1172-1189.
Robertson, A. and J. H. Louw. 1966. Polymorphism of genes affecting amount and distribution of black pigment in the abdominal cuticle of D. melanogaster. Dros. Inf. Serv 41:154-155.

Robertson, A., D. A. Briscoe, and J. H. Louw. 1977. Variation in abdomen pigmentation in Drosophila melanogaster females. Genetica 47:73-76.

Rohde, C. and V. L S. Valente. 1996. Ecological characteristics of urban populations of Drosophila polymorpha Dobzhansky and Pavan and Drosophila cardinoides Dobzhansky and Pavan (Diptera, Drosophilidae). Revta bras. Entomol 40:75-79.

Rosenberg, M. S. 2002. PASSAGE. Pattern analysis, spatial statistics, and geographic exegesis. School of Life Sciences, Arizona State University, Tempe, AZ.

Schmidt, P. S. and D. M. Rand. 1999. Intertidal microhabitat and selection at Mpi: Interlocus contrasts in the northern acorn barnacle, Semibalanus balanoides. Evolution 53:135-146.

Sene, F. M., F. C. Val, C. R. Vilela, and M. A Q. R. Pereira. 1980. Preliminary data on the geographical distribution of Drosophila species within morphoclimatic domains of Brazil. Pap. Avul. Dep. Zool. Sec. Agric 33:315-326.

Smith, T. B., R. K. Wayne, D. J. Girman, and M. W. Bruford. 1997. A role for ecotones in generating rainforest biodiversity. Science 276:1855-1857.

Storz, J. F. 2002. Contrasting patterns of divergence in quantitative traits and neutral DNA markers: analysis of clinal variation. Mol. Ecol 11:2537-2551.

Templeton, A. R. 2004. Statistical phylogeography: methods of evaluating and minimizing inference errors. Mol. Ecol 13:789-809.

Templeton, A. R. and C. F. Sing. 1993. A cladistic analysis of phenotypic associations with haplotypes inferred from restriction endonuclease mapping .4. Nested analyses with cladogram uncertainty and recombination. Genetics 134:659-669.

Templeton, A. R., E. Boerwinkle, and F. Sing. 1987. A cladistic analysis of phenotypic associations with haplotypes inferred from restriction endonuclease mapping. I. Basic theory and an analysis of alcohol dehydrogenase activity in Drosophila. Genetics 117:343-351.

Templeton, A. R., K. A. Crandall, and C. F. Sing. 1992. A cladistic analysis of phenotypic associations with haplotypes inferred from restriction endonuclease mapping and DNA sequence data. 3. Cladogram estimation. Genetics 132:619-633.

Templeton, A. R., E. Routman, and C. A. Phillips. 1995. Separating population structure from population history: a cladistic analysis of the geographical distribution of mitochondrial DNA haplotypes in the tiger salamander, Ambystoma tigrinum. Genetics 140:767-782.

Tidon-Sklorz, R. and Fd M. Sene. 1992. Vertical and temporal distribution of Drosophila (Diptera, Drosophilidae) species in a wooded area in the state of Sao Paulo, Brazil. Rev. Brasil. Biol 52:311-317.

Tidon-Sklorz, R., C. R. Vilela, Fd M. Sene, and M. A Q. R. Pereira. 1994. The genus Drosophila (Diptera, Drosophilidae) in the Serro do Cipo, state of Minas Gerais, Brazil. Revta bras. Ent 38:627-637.

True, J. R. 2003. Insect melanism: the molecules matter. Trends Ecol. Evol 18:640-647.

Vilela, C. R., A. F G. da Silva, and Fd M. Sene. 2002. Preliminary data on the geographical distribution of Drosophila species within morphoclimatic domains of Brazil. Revta. Bras. Ent 46:139-148.

Wittkopp, P. J., K. Vaccaro, and S. B. Carroll. 2002a. Evolution of yellow gene regulation and pigmentation in Drosophila. Curr. Biol 12:1547-1556.

Wittkopp, P. J., J. R. True, and S. B. Carroll. 2002b. Reciprocal functions of the Drosophila Yellow and Ebony proteins in the development and evolution of pigment patterns. Development 129:1849-1858.

Wittkopp, P. J., B. L. Williams, J. E. Selegue, and S. B. Carroll. 2003a. Drosophila pigmentation evolution: Divergent genotypes underlying convergent phenotypes. Proc. Natl. Acad. Sci. USA 100:1808-1813.

Wittkopp, P. J., S. B. Carroll, and A. Kopp. 2003b. Evolution in black and white: genetic control of pigment patterns in Drosophila. Trends Genet 19:495-504. 